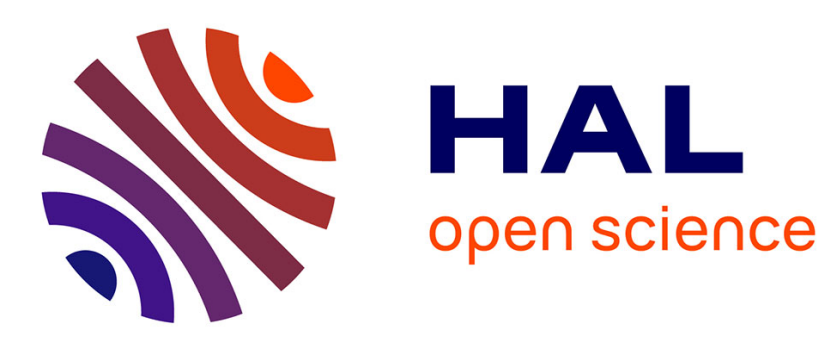

\title{
Replenishment Planning of Fresh Meat Products: Case Study from a Danish Wholesaler
}

Flemming Christensen, Iskra Dukovska-Popovska, Kenn Steger-Jensen

\section{To cite this version:}

Flemming Christensen, Iskra Dukovska-Popovska, Kenn Steger-Jensen. Replenishment Planning of Fresh Meat Products: Case Study from a Danish Wholesaler. IFIP International Conference on Advances in Production Management Systems (APMS), Sep 2017, Hamburg, Germany. pp.130-138, 10.1007/978-3-319-66926-7_16. hal-01707275

\section{HAL Id: hal-01707275 \\ https://hal.inria.fr/hal-01707275}

Submitted on 12 Feb 2018

HAL is a multi-disciplinary open access archive for the deposit and dissemination of scientific research documents, whether they are published or not. The documents may come from teaching and research institutions in France or abroad, or from public or private research centers.
L'archive ouverte pluridisciplinaire HAL, est destinée au dépôt et à la diffusion de documents scientifiques de niveau recherche, publiés ou non, émanant des établissements d'enseignement et de recherche français ou étrangers, des laboratoires publics ou privés. 


\title{
Replenishment Planning of Fresh Meat Products: Case Study from a Danish Wholesaler
}

\author{
Flemming M. M. Christensen ${ }^{1}$, Iskra Dukovska-Popovska ${ }^{1} \&$ Kenn $_{\text {Steger-Jensen }}^{1,2}$ \\ ${ }^{1}$ Centre for Logistics (CELOG), Department of Mechanical, Manufacturing and Management \\ Engineering, Aalborg University, Denmark \\ fmmcemake.aau.dk \\ ${ }^{2}$ Faculty for Technology and Maritime, Department of Maritime Technology, Operations and \\ Innovation, University College of Southeast Norway, Norway
}

\begin{abstract}
Replenishment planning of meat products with short shelf life is studied through a Danish wholesaler case-study. Main findings are that timeliness and frequency of information sharing adapted to demand dynamics can derive higher service level, and, that increased collaboration, regardless of integration, is important to obtain higher service levels. This study suggests uniform planning for both normal and campaign demand to enhance service level and profit for the normal demand.
\end{abstract}

Keywords: Collaboration · Integration · Replenishment planning $\cdot$ Fresh meat · Perishable

\section{Introduction}

Today, consumers have increasing power and requirements to the highly competitive grocery sector [1], demanding low price, at the same time with high availability, quality (i.e. freshness of products) and variety of products [2]. This has led to increasing collaboration across the supply chain, differentiated demand planning (campaign versus normal sale) [3] and emerging of replenishment programs [4], overcoming e.g. the lack of visibility of downstream sales, plans and inventory levels through distributing responsibility of planning according to competences and capabilities [5-10]. Albeit benefits of the collaborative programs (such as Efficient Consumer Response (ECR) and Collaborative Planning, Forecasting and Replenishment (CPFR)) are well documented, Mena et al. [11] find only few instances of these initiatives being used in practice.

Therefore, it is relevant to investigate how the replenishment is conducted in practice and what is the effect of it on the service level. The purpose of this study is to investigate if the differentiated planning approach as described in theory for different contexts (i.e. normal and campaign sale) applies for fresh meat products with shelf life less than 14 days. This is studied with one of Denmark's biggest wholesalers supplying the second largest and fastest growing discount retail chain in Denmark, which has not implemented a specific replenishment program. Moreover, the collaboration and information sharing (i.e. replenishment program) required to ensure downstream requirements for

adfa, p. 1, 2011.

(C) Springer-Verlag Berlin Heidelberg 2011 
availability is studied. By comparing the wholesaler's approach against existing replenishment programs, it is possible to identify how collaboration and integration plays role on the replenishment performance. Focus is on meat products with shelf life up to 14 days. The following presents the theoretical background for collaboration, integration and structure of existing replenishment programs. Next, the methodology is presented followed by presentation of the case study, the analysis, discussion and conclusion.

\section{Theoretical Framework}

Replenishment programs can be categorized as either non-collaborative traditional replenishment (TR) or collaborative automated replenishment programs (ARP). Whereas TR is a one-time replenishment, ARP can be executed through different concepts like, efficient replenishment (ER), continuous replenishment program (CRP), vendor-managed and -owned inventory (VMI and VOI), collaborative buyer-managed forecasting (CBMF) and collaborative planning, forecasting and replenishment planning (CPFR). A literature study on TR and ARP programs is conducted and their main characteristics across a number of parameters are shown in Table 1. In general literature differs between the different replenishment programs through level of collaboration and integration with supply chain stages, and the (quantitative and/or qualitative) information shared $[12,13]$.

Table 1. Collaboration and Context Characteristics of Replenishment Programs

\begin{tabular}{|c|c|c|c|c|c|c|}
\hline Parameters & TR & ER & CRP & VMI/VOI & CBMF & CPFR \\
\hline information sharing level (col) & $\begin{array}{l}\text { very } \\
\text { low }\end{array}$ & low & medium & medium & high & very high \\
\hline information shared (col) & $\begin{array}{c}\text { placed } \\
\text { order }\end{array}$ & $\begin{array}{l}\text { placed } \\
\text { order }\end{array}$ & $\begin{array}{l}\text { incoming o } \\
\text { cast, invento } \\
\text { tions, upcon } \\
\text { performance } \\
\text { sche }\end{array}$ & $\begin{array}{l}\text { sales fore- } \\
\text { vel, promo- } \\
\text { campaigns, } \\
\text { ics, delivery } \\
\text { s... }\end{array}$ & $\begin{array}{l}\text {... historical } \\
\text { consumption } \\
\text { patterns, mar- } \\
\text { ket-product in- } \\
\text { telligence... }\end{array}$ & $\begin{array}{l}\ldots \text { long- } \\
\text { term } \\
\text { goals and } \\
\text { plans }\end{array}$ \\
\hline demand-input (col) & $\begin{array}{l}\text { hist. } \\
\text { orders }\end{array}$ & POS & POS & POS & POS & POS \\
\hline developer of forecast (col) & $\mathrm{W}$ & $\mathrm{W}$ & W & $\mathrm{S}$ & $\mathrm{W} / \mathrm{S}^{1}$ & $\mathrm{~W} \& \mathrm{~S}$ \\
\hline replenishment responsible (col) & W & $\mathrm{W}$ & $\mathrm{W}\left(/ \mathrm{S}^{2}\right)$ & S & $\mathrm{S}$ & $\mathrm{W} \& \mathrm{~S}$ \\
\hline order dispatcher $(\mathrm{col})$ & $\mathrm{W}$ & $\mathrm{W}$ & $\mathrm{W}$ & $\mathrm{S}$ & $\mathrm{S}$ & $\mathrm{S}$ \\
\hline collaborative planning (col) & no & no & $(y e s)^{3}$ & no & yes & yes \\
\hline planning time-horizon (col) & short & short & medium & short & medium & long \\
\hline relationship-term $(\mathrm{col})$ & short & medium & medium & long & long & long \\
\hline demand pattern (con) & any & any & stable & stable & $\begin{array}{l}\text { stable with ex- } \\
\text { ception }\end{array}$ & $\begin{array}{c}\text { less sta- } \\
\text { ble }\end{array}$ \\
\hline product type (con) & $\begin{array}{l}\text { all } \\
\text { types }\end{array}$ & all types & all types & standard & $\begin{array}{l}\text { intro \& } \\
\text { seasonal }\end{array}$ & critical \\
\hline
\end{tabular}

The (external) integration is the configuration-oriented structuring and connection of processes and data to better facilitate the flow and availability of information, products and services between supply chain stages [16-18], hence how to share. The programs range from no integration, connecting through paper, call, fax or email (i.e. TR), to electronic data interchange (EDI) (i.e. ER, CRP and VMI/VOI) to internet-based 
integration (i.e. CBMF and CPFR). (External) collaboration is the relational and informational cooperation for working across organisational boundaries and sharing resources (information, people and technology) resulting in competitive advantage [1618], hence what and how much to share. TR entails very low collaboration, low information sharing, and decentralized forecasting and inventory management. ARP enables collaborating supply chain stages, enhancing service provided to downstream stages, by sharing "information in advance and work together to develop realistic, informed and detailed estimates that can be used to guide business operations" [8]. Depending on the ARP program, information sharing is from merely placed order to extensive sharing of e.g. point-of-sales, inventory levels and strategies [6, 19], allowing replenishments based on actual sales, resulting in higher product availability at lower costs [5]. During time, ARP has moved towards more information sharing proportionally between supply chain stages with only VMI/VOI deviating (greater buyer sharing) $[6$, 14]. The programs are either supplier (i.e. VMI/VOI), buyer (i.e. TR and ER) or equally dominated (i.e. CRP), or, distinct collaborative (i.e. CBMF and CPFR). The evolvement of programs have focused from single-transaction relationship (i.e. TR) to medium $(<12$ months) to long-term ( $>12$ months) relationship. For planning, CPFR is long-term ( $>12$ months), CRP and CBMF medium-term (6-12 months) and the remaining primarily short-term programs ( $<6$ months). The programs relate to different contexts, e.g. VMI for standard products stable demand, CPFR for critical products with less stable demand (compared to VMI) and CBMF for introduction of and seasonal products with exceptions demand [10].

\section{$3 \quad$ Methodology}

This study presents an empirical case-study research, following Flynn's six-stage framework for explorative case study [20], about fresh meat products' replenishment planning and the level of collaboration and information sharing to ensure downstream availability. Since both context and delivery performance are important in this case, studying the phenomenon in depth in natural context allows rich insight and good understanding of existing experiences [21,22]. To provide a generalizable view of replenishment planning, focus is on four different types of meat products at on one of the biggest and fastest growing retail chains in Denmark and its 16 different first tier suppliers. Due to commercial confidentiality, the company is called ABC throughout this article, and, data is indexed per mean values or stated in percentage. To strengthen validity of the study, four types of meat products with short shelf life are in focus, beef, pork, chicken and fish. Information and data for understanding the different replenishment processes was gathered through semi-structured interviews with product manager and purchasers, evolving from standardized questions. Quantitative data for the whole year 2016 about ordered and delivered amounts has been extracted from the company's enterprise resource planning (ERP) system, for all shops on daily level per SKU with shelf life of two weeks or less. In total, 46,356 unique data points (ordered and delivered quantities) are identified, categorized as either normal or campaign sale, for meat type, with service level to shops as performance indicator. 


\section{Case Study}

$\mathrm{ABC}$ is part of Scandinavia's biggest player within grocery and service trading. A centralized warehouse supplies the almost 300 discount shops in Denmark, receiving products either on Mondays, Wednesdays and Fridays (MWF-shops), or, Tuesdays, Thursdays and Saturdays (TTS-shops). ABC's overall goal is to be Scandinavia' most value-driven company and uses service level as primary performance indicator. In 2016, ABC supplied 201 different SKUs (53 beef, 45 chicken, 70 pork and 33 fish) from 16 suppliers (five for beef, two for chicken, seven for pork and two for fish). All products have the same lead-time from order dispatch to delivery, down to 36 hours.

For meat products, $\mathrm{ABC}$ uses a so-called "transit"-flow where products are ordered in exact amounts with no stock keeping, six days per week. The replenishment and planning cycles are presented in Figure 1 at a time continuum, where activities above the timeline are for assortment sale and below the timeline for campaign sale.

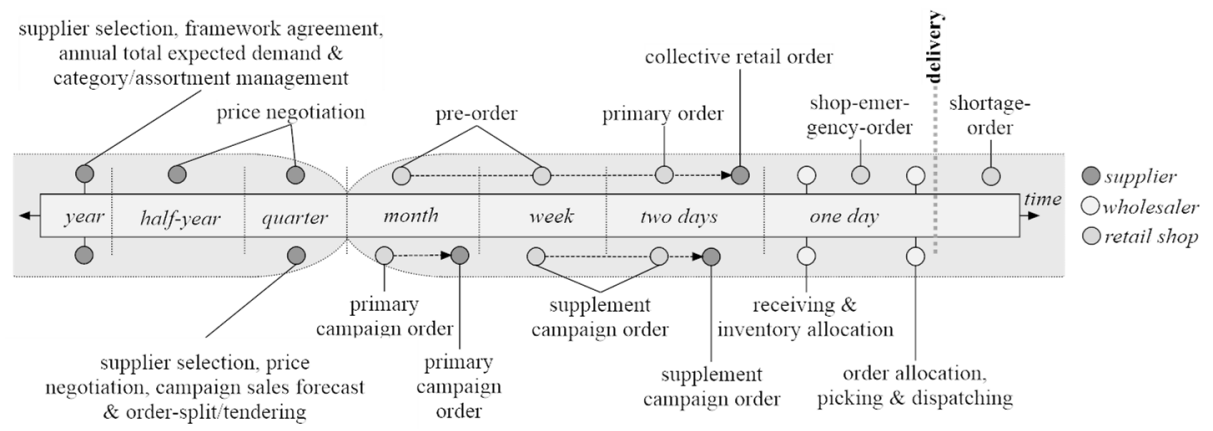

Fig. 1. Time Continuum for Replenishment Planning Activities

For assortment products, shops send orders via computer or handheld order-terminal to ABC's ERP-system via EDI at latest 18:00 two days before expected delivery. From 18:00 to 19:00, $\mathrm{ABC}$ sums up and aggregates all shop-orders into orders for each supplier. Shortly after 19:00, ABC sends orders to suppliers manually via mail or automatically via EDI (vast amount) depending on the supplier's IT-system. For products on campaign, shops send a primary order four weeks in advance and $\mathrm{ABC}$ forwards these to supplier as totals similarly four weeks in advance. If a shop has orders too few or too many products on its primary order, it has the option of dispatching supplementing orders or reducing existing order, up until two days before delivery. The day after placing the orders, between 06:00 and 15:00 (down to 11 hours after order dispatch), the products arrive to $\mathrm{ABC}$. After registering and reporting all incoming deliveries to the warehouse management system (WMS), information is transferred to the ERP-system. If a shop has not send an order the day before in due time, $\mathrm{ABC}$ may accept the order as an emergency order, depending on the reason (e.g. IT breakdown) and if the supplier can deliver the additional amount(s). In extreme cases, if supplier cannot deliver, $\mathrm{ABC}$ reduces other large shop-orders selectively by a few to accommodate the emergency order. Shop-orders are transferred from ERP-system to the WMS, ready for picking, 
from around 16:00. Received and delayed (same-day) incoming quantities are allocated to the individual shop-orders. Between 20:00 and 04:00 the next day, products are picked and packed, and dispatched from $\mathrm{ABC}$ to the shops from around 02:00 until around 07:00 in the morning.

$\mathrm{ABC}$ negotiates price for assortment products, with suppliers every three to six months. If there are several potential suppliers for a product, $\mathrm{ABC}$ may choose a different supplier with lower price, and, same or higher quality and delivery degree. For campaign-products, to assure competitive pricing, $\mathrm{ABC}$ sends demand forecast to suppliers via a tendering-like process, approximately three months prior to campaign start. Depending on price, quality and delivery degree, and if a single supplier can supply total expected demand, a single/several supplier(s) is/are chosen. If several, ABC splits the orders according to capacity available at each supplier. At annual meetings, typically in November and early December, $\mathrm{ABC}$ and suppliers agree upon a framework agreement (logistics terms, payment terms etc.), and $\mathrm{ABC}$ informs suppliers about total expected sales for upcoming year and category/assortment changes.

$\mathrm{ABC}$ has limited integration with suppliers (only EDI for some) and the collaboration is higher for campaign sale than for normal sale. Whereas ABC expects suppliers to supply normal demand without any further notice, $\mathrm{ABC}$ shares campaign demand forecasts and shop-orders, respectively three months and four weeks in advance. This, to notify the supplier about upcoming deviating demand behaviour, allowing him to plan and source raw materials accordingly. Interviews with procurement departments further highlighted that shops typically order $20-25 \%$ below actual demand when sending orders months in advance - but suppliers know this (from historical order data and behaviour) and adjust their internal plans accordingly.

$\mathrm{ABC}$ integrates with shops through EDI in order receiving, and does not collaborate any further when planning, leaving shops with individual responsibility in planning. If ordered too many products, shops may change the primary order up until normal deadline for order-dispatch (18:00 two days before delivery). However, changes allowed are smaller and smaller the closer to deadline. If supplementing orders exceed supplier' capacity, the available amount of raw materials to produce ordered product-quantities is split between the two upcoming deliveries to ABC (i.e. MWF- and TTS-shops), allowing all shops to receive products.

\section{$5 \quad$ Analysis}

\subsection{Comparing Normal \& Campaign Demand \& Service Levels}

The quantitative investigation showed that $\mathrm{ABC}$ during 2016 faced a demand of more than 5.5 million boxes of meat products with shelf life less than 14 days (beef/pork/chicken/fish). Upper part of Table 2 provides statistical information about the demand throughout the year for each meat-type, where $N$ is number of days with a demand (campaign or normal) during the year. Values are indexed against mean demand for each meat types' demand type (hence, all have a mean value of 100 ). For $50 \%$ of the observations (IQR), campaign demand deviates up to 3.7 times more across an up to 3.5 times broader range than normal demand. In terms of demand distributions' 
peaking behaviour (i.e. kurtosis), campaign demand is very leptokurtic, and normal demand is comparable almost mesokurtic (even platykurtic for fish) with a more flat and "random" demand pattern. Looking at skewness, campaign demand has a higher frequency of less-than-mean as opposed to normal demand's more symmetrical distribution with tendency of higher frequency of above-mean demand. Campaign demand is characterized by few large and many small campaigns, normal demand is characterised by few small and many large demand observations. Lower part of Table 2 summarizes service levels for product and demand types. The analysis showed a mean delivery degree for all meat products of $97.99 \%$. The service level for campaign deliveries is characterized by being more negatively skewed and more frequently closer to $100 \%$ than for normal deliveries. Oppositely the demand behaviour, service level for normal deliveries fluctuates more and over broader range. Service level for $75 \%$ of campaign deliveries are above 99.2\% (beef), 99.7\% (pork and chicken) and 98.5\% (fish) - all with leptokurtic distribution around $99.9 \%$ (beef, 99.8\%). $75 \%$ of normal deliveries' service levels are $6.4 \%$ (beef), $0.5 \%$ (pork), $4.9 \%$ (chicken) and $2.6 \%$ (fish) lower than for campaign. Figure 2 illustrates campaign versus normal demand service levels (circles are campaign sale and triangles normal), showing that campaign deliveries, regardless order size, generally have higher service levels than normal, with only fish products having a more scattered relation.

Table 2. Group-Indexed Demand and Service Levels of Meat Products, Year 2016

\begin{tabular}{lccccccc}
\hline Demand & & $\boldsymbol{N}$ & Mean \pm SD & Median & IQR & Kurtosis & Skewness \\
\hline Beef & $\mathrm{C}$ & 310 & $100 \pm 84.791$ & 80.510 & $49.341-126.836$ & 14.455 & 2.963 \\
& $\mathrm{~N}$ & 312 & $100 \pm 24.567$ & 103.159 & $82.346-116.596$ & 0.354 & -0.431 \\
\hline Pork & $\mathrm{C}$ & 309 & $100 \pm 77.241$ & 80.192 & $51.403-131.288$ & 10.518 & 2.549 \\
& $\mathrm{~N}$ & 312 & $100 \pm 21.049$ & 100.141 & $88.452-111.334$ & 3.215 & -0.266 \\
\hline Chicken & $\mathrm{C}$ & 304 & $100 \pm 65.339$ & 89.945 & $48.961-128.301$ & 2.859 & 1.433 \\
& $\mathrm{~N}$ & 312 & $100 \pm 28.302$ & 99.111 & $81.914-118.459$ & 0.344 & 0.002 \\
\hline Fish & $\mathrm{C}$ & 297 & $100 \pm 113.162$ & 71.387 & $34.425-117.625$ & 27.229 & 4.140 \\
& $\mathrm{~N}$ & 312 & $100 \pm 40.590$ & 106.716 & $66.212-133.564$ & -0.986 & -0.198 \\
\hline Service level & & $\mathbf{n}$ & $\mathbf{M e a n} \pm \mathbf{S D}$ & Median & $\mathbf{I Q R}$ & Kurtosis & Skewness \\
\hline Beef & $\mathrm{C}$ & 310 & $0.983 \pm 0.048$ & 0.998 & $0.992-1.000$ & 39.556 & -5.531 \\
& $\mathrm{~N}$ & 312 & $0.956 \pm 0.045$ & 0.973 & $0.928-0.995$ & 0.195 & -1.004 \\
\hline Pork & $\mathrm{C}$ & 309 & $0.994 \pm 0.019$ & 0.999 & $0.997-1.000$ & 29.189 & -5.145 \\
& $\mathrm{~N}$ & 312 & $0.992 \pm 0.017$ & 0.998 & $0.992-0.999$ & 31.859 & -4.765 \\
\hline Chicken & $\mathrm{C}$ & 304 & $0.994 \pm 0.024$ & 0.999 & $0.997-1.000$ & 80.260 & -8.297 \\
& $\mathrm{~N}$ & 312 & $0.966 \pm 0.050$ & 0.990 & $0.948-0.999$ & 6.578 & -2.272 \\
\hline Fish & $\mathrm{C}$ & 297 & $0.934 \pm 0.173$ & 0.999 & $0.985-1.000$ & 11.552 & -3.356 \\
& $\mathrm{~N}$ & 312 & $0.962 \pm 0.069$ & 0.996 & $0.959-0.999$ & 9.464 & -2.819 \\
\hline
\end{tabular}

$C=$ campaign sales, $N=$ normal sales
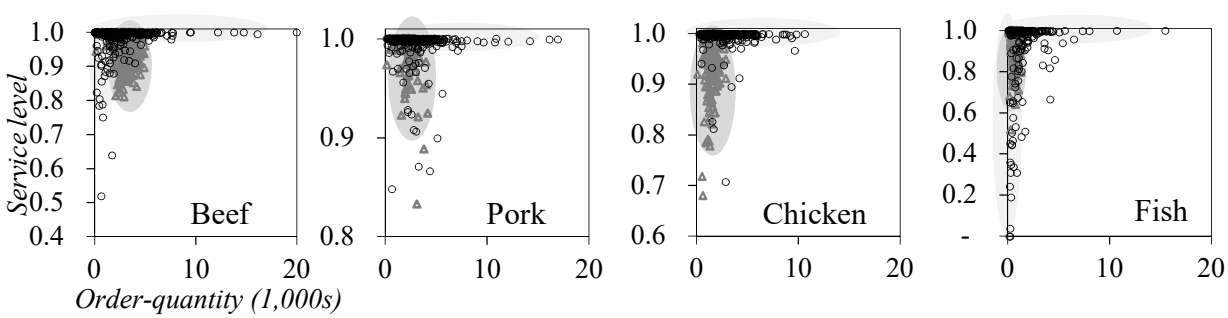

Fig. 2. Campaign \& Normal Service Levels versus Order Size for Meat Products 


\subsection{Replenishment Planning}

$\mathrm{ABC}$ uses aspects from different replenishment programs, depending on whether the planning regards normal or campaign demand. $\mathrm{ABC}$ ' approach for normal demand is similar to those of low collaboration (e.g. TR and ER). There is no distinctive collaboration and integration with suppliers, sharing only orders through mail or EDI and planning is individual, based on historical orders. For campaign demand, ABC' approach is more like those of higher collaboration (e.g. CBMF and CPFR) in that of close collaboration and sharing of forecasted demand, incoming orders, upcoming campaigns and medium to long-term plans - yet with no distinctive integration. Since ABC acts as facilitator for the shops by negotiating price, adjusting assortment to shops' requirements and balancing the converging-diverging product flow, $\mathrm{ABC}$ has no distinct decision-making in order dispatching and replenishment planning in shops. $\mathrm{ABC}$ merely aggregates and forwards incoming orders to suppliers. Based upon the differences in replenishment planning and performed service levels for respectively normal and campaign demand, it is desirable to share more information and collaborate closer for normal demand, to create higher service levels for normal demand.

\section{Discussion \& Conclusion}

One of the main findings is that information sharing timeliness and frequency adapted to the demand dynamics can derive higher service level from supplier to ABC to the shops (given the transit flow), thus greater revenue. For ABC, simply sharing demand data in advance for all demand types may lead to (perfectly) $100 \%$ service levels, giving an estimated revenue growth of $2.6 \%$ (more than USD 2.75 million) plus additional increase due to the constant availability. The literature suggests that a company' performance is relatively influenced by level of collaboration, and further enhanced by the level of integration [18] due to the suggested information sharing frequencies. For TR and ARP programs, level of integration is relative to the level of collaboration (TR versus ER/CRP/VMI/ VOI versus CBMF/CPFR). This is justified by the appropriateness of the programs relative to the context, e.g. CPFR and CBMF for campaign sale. However, two interlinked factors evident in the case study suggest that only collaboration is important to obtain high service levels, regardless context, and that integration does not play any role. This can be explained by two interlinked factors. First factor is the three-stage supply chain (supplier, wholesaler and shops), opposite to ARP programs mainly two-stages. By including three stages, the wholesaler's consolidating function allows reducing the need for integration. Albeit the main-reason for integration is to increase efficiency by better facilitating the flow and availability of information, (particularly) when having several downstream entities, case study suggests that the consolidating role of wholesaler makes the need of integration less, since the downstream flow of information is combined and unified into one upstream flow. Second factor is wholesaler' role as a transit point, where products are not stored for longer time. Meat products are, due to the rapid degradation, moved through the supply chain fast and produced down to 36 hours before delivery, following the make-to-order principle, delaying the production decoupling point. 
This research has focused on major common meat types in grocery business, and more research is needed for other types to establish the level of validity in using nonintegrated and uniform planning. The meat types in focus are with constant demand throughout the year, and other meat types may be influenced by e.g. seasonality or only sold for a certain period during the year. Also, this research has focused on discount shops which are heavily influenced by low price, availability, large amounts sold during campaign and high frequency of campaigns. Additional research is needed for other store-types such as convenience stores and hypermarkets with different characteristics (e.g. different campaign frequency and/or price level).

\section{References}

1. Fernie, J., Sparks, L., McKinnon, A.C.: Retail Logistics in the UK: Past, Present and Future. Int. J. Retail Distrib. Manag. 38, 894-914 (2010).

2. Jacobsen, P.Ø., Bjerre, M.: Effekt \& Effektivitet, Dansk Dagligvarehandel 2003-2013. Copenhagen Business School (2015).

3. Adebanjo, D.: Understanding Demand Management Challenges in Intermediary Food Trading: A Case Study. Supply Chain Manag. An Int. J. 14, 224-233 (2009).

4. Whipple, J.M., Russell, D.: Building Supply Chain Collaboration: a Typology of Collaborative Approaches. Int. J. Logist. Manag. 18, 174-196 (2007).

5. Stank, T.P., Daugherty, P.J., Autry, C.W.: Collaborative Planning: Supporting Automatic Replenishment Programs. Supply Chain Manag. An Int. J. 4, 75-85 (1999).

6. Derrouiche, R., Neubert, G., Bouras, A.: Supply Chain Management: a Framework to Characterize the Collaborative Strategies. Int. J. Comput. Integr. Manuf. 21, 426-439 (2008).

7. Kubde, R.A., Bansod, S. V.: Collaborative Planning Forecasting and Replenishment Initiatives: A State of Art. Asian J. Ind. Eng. 2, 89-104 (2010).

8. Sabath, R.E., Autry, C.W., Daugherty, P.J.: Automatic Replenishment Programs: the Impact of Organizational Structure. J. Bus. Logist. 22, 91-105 (2001).

9. Attaran, M., Attaran, S.: Collaborative Supply Chain Management: The most Promising Practice for Building Efficient and Sustainable Supply Chain. Bus. Process Manag. J. 13, 390-404 (2007)

10. Alftan, A., Kaipia, R., Loikkanen, L., Sepns, K.: Centralised Grocery Supply Chain Planning: Improved Exception Management. Int. J. Phys. Distrib. Logist. Manag. 45, 237-259 (2015).

11. Mena, C., Terry, L.A., Williams, A., Ellram, L.: Causes of Waste across Multi-Tier Supply Networks: Cases in the UK Food Sector. Int. J. Prod. Econ. 152, 144-158 (2014).

12. Chopra, S., Meindl, P.: Supply Chain Management: Strategy, Planning and Operation. Pearson, New Jersey (2010).

13. Lambert, D.M.: Supply Chain Management - Processes, Partnership, Performance. Supply Chain Management Institute, Sarasota (2008).

14. Verheijen, B: Drivers for Supply Chain Collaboration in Practice. In: PhD-thesis: Vendor-Buyer Coordination in Supply Chains. pp. 9-42. Erasmus Research Institute of Management, Rotterdam (2010).

15. Reyes, P.M., Bhutta, K.: Efficient Consumer Response: Literature Review. Int. J. Integr. Supply Manag. $1,346-386(2005)$.

16. Natour, A., Gibson, P., Gibson, P.: Supply Chain Integration and Collaboration for Performance Improvement: an Agency Theory Approach. In: 9th ANZAM Operations, Supply Chain and Services Management Symposium. pp. 503-519., Geelong (2011).

17. Moharana, H., Murty, J.S., Senapati, S.K., Khuntia, K.: Coordination, Collaboration and Integration for Supply Chain Management. Int. J. Intersci. Manag. Rev. 2, 46-50 (2012).

18. Kache, F., Seuring, S.: Linking Collaboration and Integration to Risk and Performance in Supply Chains via a Review of Literature Reviews. Supply Chain Manag. An Int. J. 19, 664-682 (2014).

Simchi-Levi, D., Kaminsky, P., Simchi-Levi, E.: Supply Chain Integration. In: Designing \& Managing the Supply Chain: Concepts, Strategies \& Case Studies. pp. 119-143. McGraw-Hill, New York (2003).

Flynn, B.: Empirical Research Methods in Operations Management. J. Oper. Manag. 9, 250-284 (1990).

Yin, R.K.: Case Study Research: Design and Methods. SAGE Publications Inc, California (2014).

Eisenhardt, K.M.: Building Theories from Case Study Research. Acad. Manag. Rev. 14, 532-550 (1989). 